\title{
Medical Student Education in Ambulatory Settings
}

\author{
Does It Affect Patient Satisfaction?
}

A s patient care shifted from hospital to ambulatory settings during the past 2 decades, medical schools increased student education in those settings. From 198687 to $1996-97$, the time students spent in ambulatory settings during their internal medicine clerkships increased from $6 \%$ to $28 \% .^{1}$ Although medical students seem satisfied with training in the ambulatory setting, ${ }^{2}$ there is concern that student education may have a negative impact on patient satisfaction.

Previous studies found that student involvement had little influence on patient satisfaction. ${ }^{3-5}$ These studies were observational studies subject to bias, ${ }^{6}$ even though they were well-designed observational studies. Randomized controlled trials are difficult to do in medical education. Small numbers of potential participants at any one institution and practical issues of modifying educational programs and clinical settings for research purposes hinder most educational research.

In this issue of the Journal of General Internal Medicine, Gress et al. report the first randomized controlled trial of the effects of medical students' involvement in ambulatory care visits. ${ }^{7}$ This study is an example of a creative and exceptionally well-designed educational study. Gress et al. randomly assigned patients to one of two study groups: 1) attending physician only or 2) attending physician plus medical student. Random assignment was done in pairs to further control for potential bias from visit type (new versus return), attending physician, and date of visit. This produced 2 groups of patients that were equivalent in characteristics that might influence patient satisfaction (age, sex, income). A staged interview was done to preserve blinding of study group assignment during questioning about satisfaction with the visit, and there were specific questions related to patients' satisfaction with the medical student. These interviews were done by telephone within 72 hours of the visit, so patients were not influenced by the office setting.

Similar to prior studies, Gress et al. found no significant differences in global patient satisfaction ratings between the two study groups. Approximately $80 \%$ to $85 \%$ of patients rated their physician as "excellent" and $85 \%$ rated the overall office visit as "excellent" or "very good." However, when patients were asked directly about the medical student, only $26 \%$ of patients rated the student as "excellent," and another $44 \%$ rated the student as "very good." More importantly, 30\% of patients indicated that they would "probably not" or "definitely not" want a similar arrangement where they would be seen by a doctor in training, and 17\% would not recommend this arrangement to a friend or family member. The latter percentages are striking because these patients agreed to be seen by a medical student and participated in the study.

Clearly, this study needs to be replicated at other institutions and in other ambulatory settings (e.g., community-based offices, health maintenance organizations, family medicine and pediatric practices) to determine if the findings are robust. The authors describe in their discussion several limitations of their study that should to be addressed in future studies: a small sample size that limits the statistical power of the study, and 4 attending physicians and 4 medical students at a single academic general internal medicine practice that limits the generalizability of the results. This study also indicates that global patient satisfaction measures do not detect patients' dissatisfaction with trainee involvement in their care. New measures that are specific to student involvement in patients' care, such as the ones used in this study, should be used.

Most provocative studies raise more questions than they answer. This study is no exception. We do not know why patients who initially agreed to be seen by a medical student would or would not want to be seen by a student again. The answers to this question are important. These data would assist preceptors in selecting patients for students and educators in developing approaches for enhancing student-patient interactions. To give us a complete picture of medical education in ambulatory settings, we also need studies that explore the "value added" to patient care by trainees and the impact on job satisfaction for clinicians. Finally, we do not know if these reactions are specific to ambulatory settings. Patients may have similar reactions to medical student involvement in hospital settings.

What do we do in the meantime? We continue to be sensitive to patients' wishes and reactions regarding trainees' involvement in their care, no matter what the setting. - Martha S. Gerrity, MD, PhD, Portland Veterans Affairs Medical Center and Division of General Medicine and Geriatrics, Oregon Health and Sciences University, Portland, Ore. 


\section{REFERENCES}

1. Levinsky NG. A survey of changes in the proportions of ambulatory training in internal medicine clerkships and residencies from 1986-87 to 1996-97. Acad Med. 1998;73:1114-5.

2. Kalet A, Schwarz MD, Capponi LH, Mahon-Salazar C, Bateman WB. Ambulatory versus inpatient rotations in teaching thirdyear students internal medicine. J Gen Intern Med. 1998;13: 327-30.

3. Frank SH, Stange KC, Langa D, Workings M. Direct observation of community-based ambulatory encounters involving medical students. JAMA. 1997;278:712-6.
4. O’Malley PG, Omori DM, Landry FJ, Jackson J, Kroenke K. A prospective study to assess the effect of ambulatory teaching on patient satisfaction. Acad Med. 1997;72:1015-7.

5. Simon SR, Peters AS, Christiansen CL, Fletcher RH. Effect of medical student teaching on patient satisfaction in a managed care setting. J Gen Intern Med. 2000; 15:457-61.

6. Cook TD, Campbell DT. Quasi-Experimentation: Design and Analysis Issues for Field Settings. Boston, Mass: Houghton Mifflin Company; 1979.

7. Gress TW, Flynn JA, Rubin HR, et al. Effect of student involvement on patient perceptions of ambulatory care visits: a randomized controlled trial. J Gen Intern Med 2002;17:420-7. 